\title{
Review of the Evidence for the Use of Probiotics in Gastrointestinal Disorders
}

\author{
Tara L. Whyand ${ }^{1}$ and Martyn E. Caplin ${ }^{2 *}$ \\ ${ }^{1}$ Department of Nutrition and Dietetics, Royal Free Hospital, London, NW3 2QG, UK \\ ${ }^{2}$ Centre for Gastroenterology, Royal Free Hospital, London, NW3 2QG, UK
}

Received: September 30, 2014; Accepted: December 12, 2014; Published: December 22, 2014

*Corresponding author: Martyn E. Caplin, Centre for Gastroenterology, Royal Free Hospital, London, NW3 2QG, UK, Tel: +20-7830-2867; Fax: + 207472-6728; E-mail: m.caplin@ucl.ac.uk

\begin{abstract}
The gut microbiota fulfils important metabolic and immunological tasks, and floral imbalance may lead to the development of dysbiosis and microbiota-related diseases. The most common illnesses associated with dysbiosis include infections, inflammatory bowel disease, Irritable Bowel Syndrome (IBS), colorectal cancer, and other gastrointestinal functional diseases which cause diarrhoea directly, or indirectly through treatment. In theory, every disorder associated with dysbiosis might benefit from modulation of the gut microbiota. We review the evidence for probiotics in prevention and treatment in these gastrointestinal disorders. We found probiotic efficacy was strain specific. They are well tolerated with minimal toxicity. There appears to be selective benefit of Saccharomyces boulardii and a mixture of Lactobacillus acidophilus, Bifidobacterium bifidum, Lactobacillus bulgaricus and Streptococcus thermophilus probiotics as prophylaxis of travellers' diarrhoea. $S$. boulardii is useful in treating travellers' diarrhoea where other medical treatments have failed. For IBS, a mixture of bacterial strains including lactobacillus and bifidobacteria may be the most effective in IBS collective symptoms. Probiotics, especially those containing multiple strains can maintain remission in ulcerative colitis and also demonstrate efficacy in pouchitis. There is currently no evidence for probiotics in Crohn's disease. Lactobacillus species appear to be the most effective in preventing Clostridium difficile infections. For lactose intolerance there is most evidence for Lactobacillus rhamnosus and bifidobacterium usually in combination. Probiotics, in particular Lactobacillus and Bifidobacteria species have a beneficial role in the care of patients with diarrhoea associated chemotherapy and radiotherapy.
\end{abstract}

Keywords: Diarrhea; Probiotics; Dysbiosis; Inflammatory Bowel Diseases; Bifidobacterium; Lactobacillus

\section{Introduction}

The gastrointestinal tract naturally contains trillions of bacteria, which is estimated to account for $1-3 \%$ of total body mass [1] and collectively is known as the gastrointestinal microbiota. Most of the endogenous bacteria in healthy adults belong to just two phyla, Firmicutes and Bacteroidetes, which account for $>90 \%$ of the known phylogenetic categories of the human gastrointestinal tract [2]. They are important for maintaining not only gastrointestinal health, but they also impact on the body's immune system [3]. The balance and mix of bacteria can be affected by many different factors, including antibiotics, aging, and illnesses such as Inflammatory Bowel Disease (IBD), following infective gastroenteritis, after cancer treatment or gastrointestinal surgery.

One way of boosting the natural beneficial bacteria in the gastrointestinal tract is by increasing the level of prebiotics in the diet. Prebiotics are forms of carbohydrate that only the gut bacteria can feed upon. Good sources of prebiotics in the diet include bananas, onions, garlic, asparagus, artichoke and chicory. These foods can cause unwanted side effects however e.g. bloating and increased bowel frequency, so some prefer to consume bacteria instead and thus take a probiotic product. Probiotic bacteria are live microorganisms that, when administered in adequate amounts, confer a health benefit to the host [4]. Probiotics may elicit immunomodulatory effects through direct interactions with the intestinal epithelium, especially in the small intestine, which is less densely populated by the commensal microbiota [5]. By contrast, probiotic immunomodulatory effects in the colon, where microbiota are densely populated, are more likely to occur via modulation of the endogenous microbiota [6].

There are a few possible mechanisms by which modulation of the gut microbiota specifically improves gastrointestinal disorders, although none of this is fully understood yet.

In Irritable Bowel Syndrome (IBS), probiotics and synbiotics (probiotic and prebiotic) can correct bacterial imbalances (dysbiosis) when increased intestinal permeability and barrier dysfunction exist [7]. A decrease in microbial biodiversity and increase in fungi has been found in mucosa and faeces of IBD patients; pre-and probiotics can modulate gut microbiota [8]. The leading hypothesis for IBD and pouchitis is that dysbiosis plays an active role in inducing and maintaining persistent inflammation. The dysbiosis in pouchitis patients is characterised by reduced diversity of the microbiota, which may lead to abnormal mucosal immune regulation triggering the inflammatory processes in genetically predisposed patients [9]. Thus treating the dysbiosis is considered a treatment. In cancer, dysbiosis in the human gut microbiota after chemotherapy may favour colonisation with 
Clostridium difficile (c.difficile) and Enterococcus faecium, thus introducing competitive probiotic bacteria back into the gut may offer protection [10]. Unlike chemotherapy, it is not known which specific bacteria are involved in causing diarrhoea during pelvic radiotherapy, but there is evidence that dysbiosis occurs as a result of this treatment [11]. C. difficile is a bacterial infection in itself, resulting from gut microbiota dysbiosis. High numbers of protective bacteria, have been shown to reduce incidence of $C$. difficile infection as it is thought that some bacteria are better at competing than $C$. difficile [12]. Preventing dysbiosis is the key here, as modulating gut bacteria after infection proves difficult. In travellers' diarrhoea, the potential mechanisms by which balanced gut microbiota fights infectious diarrhoea include exclusion of pathogens by means of competition for binding sites and available substrates, lowering of luminal $\mathrm{pH}$ and production of bacteriocins, and promotion of the production of mucus [13]. Quite differently, in lactose intolerance, when some probiotics are introduced into the gut, they produce beta- galactosidase or lactase intracellularly that may assist in the digestion of lactose. These enzymes may alleviate clinical symptoms brought about by undigested lactose for other reasons (influence of colonic flora, the colonic $\mathrm{pH}$ ), and hydrogen production [14].

There are many controversies regarding probiotics. Some of these are around which type of patients can benefit from their use, or even be put at risk from their use. For example, during immunosuppression and critical illness, fungemia is theoretically possible from yeast probiotics such as $S$. boulardii. Other controversy includes the difficulty in drawing conclusions from heterogeneity of probiotic studies (Table 1). Due to such uncertainty and limited evidence, the use of probiotics is confusing for both doctor and patient.

There are many different types of probiotics which are available, some in liquid form such as fermented milk drinks and yoghurts, as well as in supplements in the form of tablets, capsules or sachets. The most commonly used probiotics for diarrhoea disorders include: Saccharomyces boulardii, Lactobacillus acidophilus (L. acidophilus), Lactobacillus brevis (L. brevis), Lactobacillus casei (L. casei), Lactobacillus rhamnosus strains (L. rhamnosus/L. rhamnosus GG), Bifidobacterium breve (B. breve), Bifidobacterium lactis (B. lactis), Bifidobacterium longum (B. longum) and Streptococcus thermophilus (S. thermophilus). These probiotic bacteria have been used in relation to travellers'

Table 1: Limitations in concluding evidence from probiotic studies.

Number of colony forming units used/alive in dose

Form of product: powder/capsule/dairy drink or yoghurt

Single strain vs. multi strain doses

Inclusion of prebiotics in the dose or diet

Treatment duration

Type of patient population

Number of patients treated

Randomisation, controls and blinding of clinical trials diarrhoea, IBS, cancer, IBD, pouchitis, C. difficile and lactose intolerance. Undoubtedly, the combination of bacterial species and dose is important, however defining the most appropriate probiotic has been largely been based more on marketing, rather than the best evidence.

\section{Methods}

Bibliographical searches were performed in Pubmed and Google scholar for the terms: travellers' diarrhoea, cancer, Clostridium difficile, inflammatory bowel disease, irritable bowel syndrome, pouchitis and lactose intolerance. The searches were combined with the generic terms; probiotic, Saccharomyces, Lactobacillus, Bifidobacterium as well as frequently used strains Saccharomyces boulardii, Lactobacillus acidophilus, Lactobacillus brevis, Lactobacillus casei, Lactobacillus rhamnosus strains including rhamnosus GG, Bifidobacterium breve, Bifidobacterium lactis, Bifidobacterium longum and Streptococcus thermophilus. For each gastrointestinal disorder, we excluded most in vitro and animal studies unless specifically relevant to the human conditions as noted above and prioritised meta-analyses, systematic (including Cochrane) reviews and randomised controlled trails (RCT's) where available. A final total of 70 papers were reviewed.

\section{Results}

\section{Travellers' Diarrhoea}

Travellers' diarrhoea is a common problem that affects $20-60 \%$ of travellers' who visit high risk parts of the world with contaminated food or water. Although cases of travellers' diarrhoea in returning residents continue to decrease on the whole, both Campylobacter and Salmonella are still the most common infections throughout the world [15]. Infections of Shigella spp, Giardia and Entamoeba spp is predominantly reported as having been associated with travel to lower income countries with less robust sanitation such as the Indian subcontinent, and Sub-Saharan and Southern Africa. For example, a study of London travellers' also found a predominance of Giardia cases in travellers returning from the Indian sub-continent, in particular Nepal [16].

Studies have demonstrated mixed results when administering probiotics to travellers. For example in a RCT study of travellers to Egypt, a mixture of L. acidophilus, B. bifidum, L. bulgaricus, and $S$. thermophilus or placebo, reduced the frequency of diarrhoea (43\% versus $71 \%$ in the placebo) [17]. Oksanen et al. [18] compared L. rhamnosus $G G$ with placebo in travellers' to Turkey, and found a reduction in diarrhoea $(23.9 \%$ versus $39.5 \%$ in the placebo group) [18]. A double blinded placebo-controlled trial of L. rhamnosus GG in United States travellers' also showed a significant effect, with diarrhoea developing in 3.9\% per day at risk compared with $7.4 \%$ in the placebo group [19].

However, other studies have failed to show a beneficial effect. In 50 travellers' to Mexico, prophylactic ingestion of a mixture of L. acidophilus and L. bulgaricus was not effective in reducing the frequency or duration of new-onset diarrhoea [20]. In a study of 
British soldiers who were deployed to Belize, participants were administered Lactobacillus there was no significant difference in the prevalence of diarrhoea between groups that received administered Lactobacillus. fermentum strain KLD, L. acidophilus or placebo. There were no significant differences in the incidence of diarrhoea between any groups after 3 weeks $(23.8 \%, 25.7 \%$ and $23.8 \%$ respectively) [21].

A meta-analysis of 12 published RCT's which met inclusion and exclusion criteria and found that $S$. boulardii and a mixture of L. acidophilus and B. bifidum probiotics appear the best at preventing travellers' diarrhea [22].

A prospective study of 96 individuals returning from abroad with at least 11 days of travellers' diarrhoea already, were given 150-450mg S. boulardii which on average halted diarrhoea within 5 days. Sixty seven percent of these patients had previously tried anti-diarrhoeal agents or antibiotics, however only $S$. boulardii worked [23].

The problem with all the studies is knowing what should be the correct combination of bacterial species within a probiotic therapy and in what dose to prescribe them. Additionally, different types of travellers' diarrhoea from different countries may require different probiotic species.

Conclusion: There appears to be selective benefit of $S$. boulardii and a mixture of L. acidophilus, B. bifidum, L. bulgaricus and $S$. thermophilus probiotics as prophylaxis of travellers' diarrhoea. S. boulardii could be useful in treating travellers' diarrhoea where other medical treatments have failed.

\section{Irritable Bowel Syndrome}

IBS affects up to $20 \%$ of the world's population and accounts for a significant proportion of visits to primary and secondary care physicians. It is known that IBS patients have abnormal reflexes and perception in response to gastrointestinal stimuli and the individual symptoms may depend on the specific neural pathways affected. Several pathogenetic factors could cause these disturbances, including: genetic, early and environmental conditioning; cognitive/emotional adaptation; abnormalities in the composition of the gut microbiota; altered response to stress and inflammatory/post infectious processes in the gastrointestinal mucosa [24]. Hypothetically, probiotics may correct or counteract some of these underlying disturbances as specific probiotic strains may modulate gastrointestinal transit, visceral hypersensitivity, intestinal gas content, and inflammatory responses. IBS lacks effective drug management and the potential for probiotics is important. One IBS trial was unable to identify a mechanism of probiotic action but speculated that efficacy must result from factors other than the presence of induced microbiota itself (i.e. through action via direct interaction with the immune system rather than via interaction with the local bacterial colony) [25]. As previously mentioned, this direct action is more likely to occur in the small intestine where the microbiota density is lower [5].

It is however important to note that effects are strain specific for each IBS symptom and one strain does not fit all [26]. Four review articles of probiotics in IBS [27-30] were subject to a meta-analysis which concluded that probiotics could improve the global IBS symptom score and reduce abdominal pain, but may not significantly affect specific IBS symptoms of diarrhoea, constipation, and/or bloating [31].

A Canadian systematic review of 19 RCT's concluded probiotics appear to be efficacious in IBS, but the magnitude of benefit and the most effective species and strain are uncertain [32]. Three studies of three probiotics evaluated diarrhoea as a secondary end point. Two studies reported no difference between specific probiotic treatments and placebo $[33,34]$ and one study reported a significant increase of diarrhoea with the probiotic compared with placebo [35]. A review of 42 RCT's looked at the effect of lactic acid bacteria on IBS symptoms [36]. Thirty-four of these trials reported benefit in at least one of the end points studied, but only the VSL\#3 mixture (L. acidophilus, L. bulgaricus, L. casei, L. plantarum, S. thermophilus, B. breve, B. infantis, B. longum) was found to reduce diarrhoea [37]. Another review of 16 RCT's found that 11 trials were not blinded well enough, were too short/small, and/or lacked intention to treat analysis [38], but they concluded that only Bifidobacterium infantis $[39,40]$ showed significant improvements in bowel movements compared with placebo.

Most recently, a European Consensus Committee following systematic review of the literature and a Delphi process of consensus concluded specific probiotics help reduce overall symptoms burden and abdominal pain in some IBS patients. Symptom improvement includes reduced bloating, distension and improvement in bowel frequency and some probiotics improved quality of life [41].

Conclusion: A mixture of bacterial strains including lactobacillus and bifidobacteria may be the most effective in IBS collective symptoms with a good safety record and are thus appropriate for therapeutic trial in holistic IBS therapy.

\section{Inflammatory Bowel Disease}

Inflammatory Bowel Disease includes Crohn's disease and ulcerative colitis, with diarrhoea being a prevalent symptom in these patients. Patients often relapse with standard medical therapies (e.g. steroids and 5-amino-salicylic acid compounds). Given that an imbalance or a severe response to intraluminal bacteria seems to be involved in the pathogenesis of inflammatory bowel disease, including pouchitis [42], probiotic therapy to modify the bacterial flora is an attractive option.

Three studies using L. rhamnosus GG concluded no effects in Crohn's disease [43-45]. In addition, a meta-analysis on eight clinical trials looking at different probiotic strains confirmed this lack of benefit [46]. There is limited evidence that $S$. boulardii probiotic given in conjunction with mesalazine can increase remission time [47], and the British Dietetic Association 2013 guidelines concludes that there does not appear to be a benefit for probiotic use in Crohn's disease patients [48].

Using probiotics in Ulcerative Colitis (UC) can induce 
remission [49]. Studies using preparations containing mainly bifidobacteria and commercial mixtures, including VSL\#3 [5056] revealed efficacy in the maintenance therapy of UC patients. In a meta-analysis of 23 RCT's only VSL\#3 significantly increased the remission rates compared with controls in patients with active UC [57]. The most recent meta-analysis states that the same formulation is also safe and more effective than conventional therapy alone in achieving higher response and remission rates in mild to moderately active ulcerative colitis [58] .

Up to $60 \%$ of patients following proctocolectomy and ilealanal pouch formation develop an inflammatory condition often associated with bowel urgency and frequency, termed pouchitis. There appears to be a derangement in the pouch microbiome hence benefit has been shown for both antibiotics and probiotics.

Studies have tended to be small and of variable length. One study used the probiotic L. rhamnosus GG [59]; the other studies used combination of probiotics [60-64], including VSL\#3. The comparison was made to placebo-treated control groups receiving maize starch or microcrystalline cellulose. The clinical efficacy of the probiotic intervention was evaluated based on clinical, histological, endoscopic and microbiological criteria, including the pouchitis disease activity index. The five studies using high dose probiotic mixture demonstrated clinical efficacy in pouchitis [60-64]. The study using L. rhamnosus GG alone observed alterations in intestinal microbiota but no other effects on clinical parameters [59]. In the most recent meta-analysis of 23 RCT's, only VSL\#3 significantly reduced the clinical relapse rates for maintaining remission in patients with pouchitis [58]. Primary prevention of pouchitis and reducing the likelihood of relapse after successful antibiotic treatment has led to the highest possible rating, an 'A' recommendation [65].

Conclusion: Probiotics, especially those containing multiple strains can maintain remission in ulcerative colitis and also demonstrate efficacy in pouchitis. There is currently no evidence for probiotics in Crohn's disease.

\section{C. difficile and antibiotic associated diarrhoea}

C. difficile is a major source of concern and infection in the hospital setting and is most frequently the result of broad spectrum antibiotic therapy. The cause is attributed to the reduction of the endogenous protective gastrointestinal microbiota [66]. C. difficile acquired diarrhoea causes $10-20 \%$ of all cases of antibiotic associated diarrhoea [67] and it can occur up to 8 weeks after antibiotic therapy [68]. A review of antibiotic associated diarrhoea in children found that Lactobacillus GG, $S$. boulardii, B. lactis and $S$. thermophilus reduced the risk of antibiotic-associated diarrhoea [69]. As evidence gathered for probiotics, it led to a Cochrane database of systematic review, evaluating their efficacy in acute infectious gastroenteritis [70]. There has also been significant interest to asses if probiotics can prevent $C$. difficile infection.

In a study of hospitalized patients, L. acidophilus alone or in combination with $L$. casei appears to prevent $C$. difficile infection
[71-74]. A dairy drink including Lactobacillus casei, Lactobacillus delbrueckii subsp. bulgaricus and S. thermophilus may also reduce rates of $C$. difficile infection [75]. A meta-analysis of 6 trials found the relative risk of getting antibiotic associated diarrhoea is significantly reduced while taking L. rhamnosus GG [76]. Despite the evidence, probiotics were considered insufficient to classify as the high grade ' $\mathrm{A}$ ' recommendation in $C$. difficile associated diarrhoea [65].

In 2013, a more recent review and meta-analysis of 23 RCT's, including 4213 patients, suggests moderate quality evidence that probiotics are both safe and effective for preventing $C$. difficileassociated diarrhoea [77]. A further systematic review and meta-analysis of 16 studies found that probiotics were safe and effective for use in preventing antibiotic associated diarrhoea and $C$. difficile in inpatients requiring antibiotics [78]. They also conclude that Lactobacillus based products are slightly better than the others to prevent this type of diarrhoea and infection [78].

Conclusion: Lactobacillus species appear to be the most effective in preventing $C$. difficile infections, but more randomised trials need to be undertaken to identify whether a single strain or a mixture of probiotics work best.

\section{Lactose intolerance}

Lactose intolerance affects $70 \%$ of the world's population [79] and is mainly caused by lactase enzyme deficiency which leads to diarrhoea and nutrient malabsorption [82]. It could be possible to reduce the symptoms of lactose intolerance i.e. diarrhoea with the use of probiotics. The replacement of dietary milk with low-lactose and L. rhamnosus enriched dairy products has been shown to prevent the symptoms of lactose intolerance [80]. Another diary drink (Yakult containing L. casei Shirota and B. breve), taken for four weeks, improved symptoms and decreased hydrogen production in lactose-intolerant patients. There was a lasting effect for at least 3 months after stopping probotic intake [81].

In post infectious IBS, secondary lactase deficiency was detected in 59.4\% of 138 patients, and all of those suffering secondary lactase deficiencies also had small intestinal bacterial overgrowth (SIBO) [82]. SIBO was confirmed using lactulose breath testing. A probiotic mixture of B. longum 107 and Enterococcus faecium 107 was administered as one capsule t.i.d. for 14 days. Restoration of eubiosis in the small bowel lumen was achieved in $70.8 \%$ of the patients, as shown by reduction in SIBO [82].

Conclusion: There is a benefit from taking probiotics in lactose intolerance. There is most evidence for L. rhamnosus and bifidobacterium, often in combination.

\section{Cancer}

Probiotics may be useful in reducing colorectal cancer risk [83], but the best evidence in human trials of colorectal cancer prevention involves synbiotics [84].

Components in our diet may affect the gut microbiota and 
influence colorectal oncogenesis. Excess fat in the diet means that more bile will be produced and more bile acids will escape the enterohepatic circulation. In the colon, these can be metabolised to mutagenic components [85]. Probiotics such as Lactobacilli metabolise heterocyclic amines and are not fermented [86]. Meat cooked at high temperatures contains high levels of heterocyclic amines which have been found to be fermented by gut microbiota and the byproducts of this process can damage DNA and increase the risk of colorectal cancer [87]. There is a completed Phase 2 trial assessing the role of probiotics on gut microbiota and colorectal cancer but the results have not been published yet [88]. The role of the VSL\#3 probiotic combinations in rectal cancer is being investigated in a phase 3 clinical trial and results are also due [89].

Some cancer therapies can be associated with gastrointestinal disturbance often including diarrhoea. The role of probiotics has been assessed in these patients. There is more information for patients with colorectal cancer [83], than other cancers at present. The theoretical risk of giving probiotics to potentially immunocompromised patients appears not to be substantiated in published studies although $S$. boulardii has been associated with fungemia [90-92]. In one randomised study of 150 patients diagnosed with colorectal cancer, half were given L. rhamnosus GG supplementation during 5-FU-based chemotherapy. $L$. rhamnosus $G G$ was well tolerated and reduced the frequency of grade 3 or 4 diarrhoea (22\% v's 37\%) and abdominal discomfort related to 5-FU-based chemotherapy [93]. In another study, 398 men and women who were free from tumour but who had at least two colorectal tumours removed were given wheat bran and/or L. casei. It was found that L. casei prevented atypia of colorectal tumours [94]. A study of 31 subjects undergoing elective colorectal resection for cancer ware given a mixture of $B$. longum and L. johnsonii. It was found that only L. johnsonii adhered to the colonic mucosa and affects intestinal microbiota by reducing the concentration of pathogens and modulates local immunity [95]. In a study of 37 high grade dysplastic /colorectal cancer patients, and 43 polypectomized patients were given a synbiotic preparation of oligofructose- enriched inulin, L. rhamnosus $G G$ and B. lactis. The number of stool Bifidobacterium and Lactobacillus increased, stool Clostridium perfringens decreased, and there was a reduction of colorectal proliferation [84]. Additionally in another study, 50 patients with colorectal carcinoma scheduled for radical colorectomy were given probiotics containing Lactobacillus plantarum, L. acidophilus and B. longum, for 16 days (six days preoperatively and ten days postoperatively). The treatment decreased the rate of postsurgical infection [96].

Patients undergoing radiotherapy may also benefit from probiotic use. Radiotherapy to the pelvic area often results in radiation-induced diarrhoea. In one study, B. bifidum and $L$. acidophilus significantly reduced both diarrhoea and use of antidiarrhoeal agents in 32 women undergoing chemo (cisplatin) -radiation therapy for cervical cancer [97]. In a double blind
Table 2: Conclusions of probiotic use in gastrointestinal disorders.

\begin{tabular}{|c|c|}
\hline Gastrointestinal Disorder & Conclusion \\
\hline Travellers' Diarrhoea & $\begin{array}{l}\text { A selective benefit of } S \text {. boulardii and a } \\
\text { mixture of } L \text {. acidophilus, B. bifidum, } L \text {. } \\
\text { bulgaricus and } S \text {. thermophilus probiotics } \\
\text { as prophylaxis of travellers' diarrhoea. } \\
\text { S. boulardii may be useful in treating } \\
\text { travellers' diarrhoea where other medical } \\
\text { treatments have failed. }\end{array}$ \\
\hline Irritable Bowel Syndrome & $\begin{array}{l}\text { A mixture of bacterial strains including } \\
\text { lactobacillus and bifidobacteria may be the } \\
\text { most effective in IBS collective symptoms } \\
\text { with a good safety record and are thus } \\
\text { appropriate for therapeutic trial in holistic } \\
\text { IBS therapy. }\end{array}$ \\
\hline $\begin{array}{l}\text { Inflammatory Bowel } \\
\text { Syndrome }\end{array}$ & $\begin{array}{l}\text { Probiotics, especially those containing } \\
\text { multiple strains can maintain remission } \\
\text { in ulcerative colitis and also demonstrate } \\
\text { efficacy in pouchitis. There is currently no } \\
\text { evidence for probiotics in Crohn's disease. }\end{array}$ \\
\hline $\begin{array}{l}\text { C. difficile and antibiotic } \\
\text { associated diarrhoea }\end{array}$ & $\begin{array}{l}\text { Lactobacillus species appear to be the } \\
\text { most effective in preventing C.difficile } \\
\text { infections. }\end{array}$ \\
\hline Lactose intolerance & $\begin{array}{l}\text { There is benefit from taking probiotics in } \\
\text { lactose intolerance. There is most evidence } \\
\text { for L. rhamnosus and bifidobacterium, } \\
\text { often in combination. }\end{array}$ \\
\hline Cancer & $\begin{array}{l}\text { Probiotics, mainly lactobacillus and } \\
\text { bifidobacteria, have a beneficial role in the } \\
\text { care of patients with diarrhoea associated } \\
\text { with chemotherapy and radiotherapy. }\end{array}$ \\
\hline
\end{tabular}

placebo controlled trial of 251 bowel, rectal and cervical cancer patients undergoing adjuvant postoperative radiation therapy after surgery for sigmoid, rectal, or cervical cancer, 1 VSL\#3 a day from the first day of radiation therapy had positive effects in the treatment group. This mixture of probiotics lead to significantly reduced number of bowel movements, much less grade 3 or 4 diarrhoea incidence (1.4\% v's 55.4\%), and also significantly increased the time until the patient had to use loperamide [98]. Other studies using single L. acidophilus found that even single probiotics improved the patients' status during pelvic radiotherapy and decreased radiation-induced diarrhoea [99].

Conclusion: Probiotics, mainly lactobacillus and bifidobacteria, have a beneficial role in the care of patients with diarrhoea associated with chemotherapy and radiotherapy.

\section{Conclusions}

The evidence has been concluded in Table 2. Undoubtedly diet will affect the endogenous gastrointestinal bacteria; however, taking a pragmatic approach, the addition of probiotics even without dietary change appears to be effective in diarrhoea associated disorders.

Defining the optimal dose and combination of probiotic species is a difficult task, especially when diet will also play an important factor. There is however good evidence for the role of 
probiotics in diarrhoeal disorders and the development of well structured, RCT's are required.

\section{References}

1. MacDougall R. NIH Human Microbiome Project defines normal bacterial makeup of the body. [Cited 2012 April 4]; Available from: http://www.nih.gov/news/health/jun2012/nhgri-13.htm

2. Eckburg PB, Bik EM, Bernstein CN, Purdom E, Dethlefsen L, Sargent M, et al. Diversity of the human intestinal microbial flora. Science. 2005; 308(5728): 1635-8.

3. Klaenhammer TR, Kleerebezem M, Kopp MV, Rescigno M. The impact of probiotics and prebiotics on the immune system. Nat Rev Immunol. 2012; 12 (10): 728-34. doi: 10.1038/nri3312.

4. FAO/WHO. Guidelines for the evaluation of probiotics in food. Report of a Joint FAO/WHO Working Group on Drafting Guidelines for the Evaluation of Probiotics in Food; Ontario, Canada. April 30, May 1, 2002: 1-11. [Cited 2014 April 4]; Available from: ftp://ftp.fao.org/es/ esn/food/wgreport2.pdf

5. Zoetendal EG, Raes J, van den Bogert B, Arumugam M, Booijink CC, Troost FJ, et al. The human small intestinal microbiota is driven by rapid uptake and conversion of simple carbohydrates. ISME J. 2012; 6 (7): 1415-1426. doi: 10.1038/ismej.2011.212.

6. Reid G, Younes JA, Van der Mei HC, Gloor GB, Knight R, Busscher HJ. Microbiota restoration: natural and supplemented recovery of human microbial communities. Nat Rev Microbiol. 2011; 9 (1): 27-38. doi: 10.1038/nrmicro2473.

7. Lee $\mathrm{KN}$, Lee OY. Intestinal microbiota in pathophysiology and management of irritable bowel syndrome. World J Gastroenterol. 2014; 20(27): 8886-97. doi: 10.3748/wjg.v20.i27.8886.

8. Scaldaferri F, Gerardi V, Lopetuso LR, Del Zompo F, Mangiola F, Boškoski I, et al. Gut microbial flora, prebiotics, and probiotics in IBD: their current usage and utility. Biomed Res Int. 2013; 2013: 435268. doi: $10.1155 / 2013 / 435268$.

9. Scarpa M, Grillo A, Scarpa M, Brun P, Castoro C, Pozza A, et al. Innate immune environment in ileal pouch mucosa: $\alpha 5$ defensin up-regulation as predictor of chronic/relapsing pouchitis. J Gastrointest Surg. 2012; 16(1): 188-201; 201-2. doi: 10.1007/s11605-011-1720-6.

10.Zwielehner J, Lassl C, Hippe B, Pointner A, Switzeny OJ, Remely M, et al. Changes in human fecal microbiota due to chemotherapy analyzed by TaqMan-PCR, 454 sequencing and PCR-DGGE fingerprinting. PLoS One. 2011; 6(12): e28654. doi: 10.1371/journal.pone.0028654.

11. Nam YD, Kim HJ, Seo JG, Kang SW, Bae JW. Impact of pelvic radiotherapy on gut microbiota of gynecological cancer patients revealed by massive pyrosequencing. PLoS One. 2013; 8(12): e82659. doi: 10.1371/journal.pone.0082659.

12. Skraban J, Dzeroski S, Zenko B, Mongus D, Gangl S, Rupnik M. Gut microbiota patterns associated with colonization of different Clostridium difficile ribotypes. PLoS One. 2013; 8(2): e58005. doi: 10.1371/journal.pone.0058005.

13. Isolauri E. Probiotics for infectious diarrhoea. Gut. 2003; 52(3): 436-7.

14. de Vrese M, Stegelmann A, Richter B, Fenselau S, Laue C, Schrezenmeir J. Probiotics--compensation for lactase insufficiency. Am J Clin Nutr. 2001; 73 (2 suppl): 421s-429s.

15. Office for National Statistics. Travel Trends 2011: London: 2011. [Cited 2014 April 4]; Available from: http://www.ons.gov.uk/ons/ index.html

16. Breathnach AS, McHugh TD, Butcher PD. Molecular epidemiology of giardiasis in South West London [poster]. The Second International Giardia and Cryptosporidium Conference, 13-18 May 2007, Centro Cultural Universitario, Morelia, Michoacan, Mexico.

17. Black FT, Andersen PL, Orskov J, Ørskov F, Gaarslev K, Laulund S. Prophylactic efficacy of lactobacilli on traveler's diarrhea. J Travel Med. 1989; 7: 333-5.

18. Oksanen PJ, Salminen S, Saxelin M, Hämäläinen P, Ihantola-Vormisto A, Muurasniemi-Isoviita L, et al. Prevention of travellers' diarrhoea by Lactobacillus GG. Ann Med. 1990; 22(1): 53-6.

19. Hilton E, Kolakowski P, Singer C, Smith M. Efficacy of Lactobacillus GG as a diarrheal preventive in travelers. J Travel Med. 1997; 4 (1):41-3.

20. de dios Pozo-Olano J, Warram JH, Gomez RG, Cavazos MG. Effect of a lactobacilli preparation on traveler's diarrhea. A randomized, double blind clinical trial. Gastroenterololgy. 1978; 74(5):829-30.

21. Katelaris PH, Salam I, Farthing MJ. Lactobacilli to prevent traveler's diarrhea? N Engl J Med. 1995; 333(20): 1360-1.

22. McFarland LV. Meta-analysis of probiotics for the prevention of traveler's diarrhea. Travel Med Infect Dis. 2007; 5(2): 97-105.

23. Kirchhelle A, Frühwein N, Tobüren D. [Treatment of persistent diarrhea with $S$. boulardii in returning travelers. Results of a prospective study]. Fortschr Med. 1996; 114(11): 136-40.

24. Serra J, Azpiroz F, Malagelada JR. Gastric distension and duodenal lipid infusion modulate intestinal gas transit and tolerance in humans. Am J Gastroenterol. 2002; 97(9): 2225-30.

25. Kajander K, Krogius-Kurikka L, Rinttila T, Karjalainen H, Palva A, Korpela R. Effects of multispecies probiotic supplementation on intestinal microbiota in irritable bowel syndrome. Aliment Pharmacol Ther. 2007; 26(3): 463-73.

26. Dai C, Zheng CQ, Jiang M, Ma XY, Jiang LJ. Probiotics and irritable bowel syndrome. World J Gastroenterol. 2013; 19(36): 5973-80. doi: 10.3748/wjg.v19.i36.5973.

27. Floch MH. Use of diet and probiotic therapy in the irritable bowel syndrome: analysis of the literature. J Clin Gastroenterol. 2005; $39(5$ suppl 3): S243-6.

28. Park J, Floch MH. Prebiotics, probiotics, and dietary fiber in gastrointestinal disease. Gastroenterol Clin North Am. 2007; 36(1): 47-63.

29. Quigley EM, Flourie B. Probiotics and irritable bowel syndrome: a rationale for their use and an assessment of the evidence to date. Neurogastroenterol Motil. 2007; 19(3): 166-172.

30. Spiller R. Review article: probiotics and prebiotics in irritable bowel syndrome. Aliment Pharmacol Ther. 2008; 28(4): 385-96. doi: 10.1111/j.1365-2036.2008.03750.x.

31. McFarland LV, Dublin S. Meta-analysis of probiotics for the treatment of irritable bowel syndrome. World J Gastroenterol. 2008; 14(17): 2650-61.

32. Moayyedi P, Ford AC, Talley NJ, Cremonini F, Foxx-Orenstein AE, Brandt LJ, et al. The efficacy of probiotics in the treatment of irritable bowel syndrome: a systematic review. Gut. 2010; 59(3): 325-332. doi: 10.1136/gut.2008.167270.

33. Kajander K, Myllyluoma E, Rajilic-Stojanovic M, Kyrönpalo S, 
Rasmussen M, Järvenpää S, et al. Clinical trial: multispecies probiotic supplementation alleviates the symptoms of irritable bowel syndrome and stabilizes intestinal microbiota. Aliment Pharmacol Ther. 2008; 27(1): 48-57.

34. Ki Cha B, Mun Jung S, Hwan Choi C, Song ID, Woong Lee H, Joon Kim $\mathrm{H}$, et al. The effect of a multispecies probiotic mixture on the symptoms and fecal microbiota in diarrhea-dominant irritable bowel syndrome: a randomized, double-blind, placebo-controlled trial. J Clin Gastroenterol. 2012; 46(3): 220-227. doi: 10.1097/ MCG.0b013e31823712b1.

35. Ligaarden SC, Axelsson L, Naterstad K, Lydersen S, Farup PG. A candidate probiotic with unfavourable effects in subjects with irritable bowel syndrome: a randomised controlled trial. BMC Gastroenterol. 2010; 10: 16. doi: 10.1186/1471-230X-10-16.

36. Clarke G, Cryan JF, Dinan TG, Quigley EM. Review article: probiotics for the treatment of irritable bowel syndrome-focus on lactic acid bacteria. Aliment Pharmacol Ther. 2012; 35(4):403-13. doi: 10.1111/j.1365-2036.2011.04965.x.

37. Kim HJ, Vazquez Roque MI, Camilleri M, Stephens D, Burton DD, Baxter $\mathrm{K}$, et al. A randomized controlled trial of a probiotic combination VSL\# 3 and placebo in irritable bowel syndrome with bloating. Neurogastroenterol Motil. 2005; 17(5): 687-96.

38. Brenner DM, Moeller MJ, Chey W, Schoenfeld PS. The utility of probiotics in the treatment of irritable bowel syndrome: a systematic review. Am J Gastroenterol. 2009; 104(4): 1033-49. doi: 10.1038/ ajg.2009.25.

39. O’Mahony L, McCarthy J, Kelly P, Hurley G, Luo F, Chen K, et al Lactobacillus and bifidobacterium in irritable bowel syndrome: symptom responses and relationship to cytokine profiles. Gastroenterology. 2005; 128(3): 541-51.

40. Whorwell PJ, Altringer L, Morel J, Bond Y, Charbonneau D, O’Mahony L, et al. Efficacy of an encapsulated probiotic Bifidobacterium infantis 35624 in women with irritable bowel syndrome. Am J Gastroenterol. 2006; 101(7): 1581-90.

41. Hungin AP, Mulligan C, Pot B, Whorwell P, Agréus L, Fracasso P, et al. Systematic review: probiotics in the management of lower gastrointestinal symptoms in clinical practice -- an evidence-based international guide. Aliment Pharmacol Ther. 2013; 38(8): 864-86. doi: 10.1111/apt.12460.

42. Mimura T, Kaminishi M, Kamm MA. Probiotics for pouchitis and its endoscopic findings. Dig Endosc. 2002; 14(2): 47-52.

43. Prantera C, Scribano ML. Probiotics and Crohn's disease. Dig Liver Dis. 2002; 34 (suppl 2): S66-7.

44. Schultz M, Timmer A, Herfarth HH, Sartor RB, Vanderhoof JA, Rath HC. Lactobacillus GG in inducing and maintaining remission of Crohn's disease. BMC Gastroenterol. 2004; 4: 5.

45. Bousvaros A, Guandalini S, Baldassano RN, Botelho C, Evans J, Ferry $\mathrm{GD}$, et al. A randomized, double blind trial of Lactobacillus GG versus placebo in addition to standard maintenance therapy for children with Crohn's disease. Inflamm Bowel Dis. 2005; 11(9): 833-9.

46. Rahimi R, Nikfar S, Rahimi F, Elahi B, Derakhshani S, Vafaie M, et al. A meta-analysis on the efficacy of probiotics for maintenance of remission and prevention of clinical and endoscopic relapse in Crohn's disease. Dig Dis Sci. 2008; 53(9): 2524-31. doi: 10.1007/s10620-0070171-0.
47. Guslandi M, Mezzi G, Sorghi M, Testoni PA. Saccharomyces boulardii in maintenance treatment of Crohn's disease. Dig Dis Sci. 2000; 45(7); 1462-4.

48. Lee J, Allen R, Ashley S, Becker S, Cummins P, Gbadamosi A, et al. British Dietetic Association evidence-based guidelines for the dietary management of Crohn's disease in adults. J Hum Nutr Diet. 2014; 27(3): 207-18. doi: 10.1111/jhn.12176.

49. Meijer BJ, Dieleman LA. Probiotics in the treatment of human inflammatory bowel diseases: update 2011. J Clin Gastroenterol. 2011; 45 Suppl: S139-44. doi: 10.1097/MCG.0b013e31822103f7.

50.Venturi A, Gionchetti P, Rizzello F, Johansson R, Zucconi E, Brigidi P, et al. Impact on the composition of the faecal flora by a new probiotic preparation: preliminary data on maintenance treatment of patients with ulcerative colitis. Aliment Pharmacol Ther. 1999; 13(8): 1103-8.

51. Ishikawa H, Akedo I, Umesaki Y, Tanaka R, Imaoka A, Otani T. Randomized controlled trial of the effect of bifidobacteria-fermented milk on ulcerative colitis. J Am Coll Nutr. 2003; 22(1): 56-63.

52. Cui HH, Chen CL, Wang JD, Yang YJ, Cun Y, Wu JB, et al. Effects of probiotic on intestinal mucosa of patients with ulcerative colitis. World J Gastroenterol. 2004; 10(10): 1521-5.

53. Kato K, Mizuno S, Umesaki Y, Ishii Y, Sugitani M, Imaoka A, et al. Randomized placebo-controlled trial assessing the effect of bifidobacteria-fermented milk on active ulcerative colitis. Aliment Pharmacol Ther. 2004; 20(10): 1133-41.

54. Tursi A, Brandimarte G, Giorgetti GM, Forti G, Modeo ME, Gigliobianco A. Low-dose balsalazide plus a high-potency probiotic preparation is more effective than balsalazide alone or mesalazine in the treatment of acute mild-to-moderate ulcerative colitis. Med Sci Monit. 2004; 10(11): 126-31.

55. Furrie E, Macfarlane S, Kennedy A, Cummings JH, Walsh SV, O’neil DA, et al. Synbiotic therapy (Bifidobacterium longum/Synergy 1) initiates resolution of inflammation in patients with active ulcerative colitis: a randomised controlled pilot trial. Gut. 2005; 54(2): 242-9.

56. Bibiloni R, Fedorak RN, Tannock GW, Madsen KL, Gionchetti P, Campieri $\mathrm{M}$, et al. VSL\#3 probiotic-mixture induces remission in patients with active ulcerative colitis. Am J Gastroenterol. 2005; 100(7): 1539-46.

57. Shen J, Zuo ZX, Mao AP. Effect of Probiotics on Inducing Remission and Maintaining Therapy in Ulcerative Colitis, Crohn's Disease, and Pouchitis: Meta-analysis of Randomized Controlled Trials. Inflamm Bowel Dis. 2014; 20(1): 21-35. doi: 10.1097/01. MIB.0000437495.30052.be.

58. Mardini HE, Grigorian AY. Probiotic Mix VSL\#3 Is effective adjunctive therapy for mild to moderately active ulcerative colitis: A metaanalysis. Inflamm Bowel Dis. 2014; 20(9): 1562-7. doi: 10.1097/ MIB.0000000000000084.

59. Kuisma J, Mentula S, Jarvinen H, Kahri A, Saxelin M, Farkkila M. Effect of Lactobacillus rhamnosus GG on ileal pouch inflammation and microbial flora. Aliment Pharmacol Ther. 2003; 17(4): 509-15.

60. Gionchetti P, Rizzello F, Venturi A, Brigidi P, Matteuzzi D, Bazzocchi $\mathrm{G}$, et al. Oral bacteriotherapy as maintenance treatment in patients with chronic pouchitis: a double-blind, placebo-controlled trial. Gastroenterology. 2000; 119(2): 305-9.

61. Gionchetti P, Rizzello F, Helwig U, Venturi A, Lammers KM, Brigidi P, et al. Prophylaxis of pouchitis onset with probiotic therapy: a double- 
blind, placebo- Controlled trial. Gastroenterology. 2003; 124(5): 1202-9.

62. Mimura T, Rizzello F, Helwig U, Poggioli G, Schreiber S, Talbot IC, et al. Once daily high dose probiotic therapy (VSL\#3) for maintaining remission in recurrent or refractory pouchitis. Gut. 2004; 53(1): 10814.

63. Kühbacher T, Ott SJ, Helwig U, Mimura T, Rizzello F, Kleessen B, et al. Bacterial and fungal microbiota in relation to probiotic therapy (VSL\#3) in Pouchitis. Gut. 2006; 55(6): 833-841. doi: 10 1136/gut 2005078303.

64. Gionchetti P, Rizzello F, Morselli C, Poggioli G, Tambasco R, Calabrese $\mathrm{C}$, et al. High-dose probiotics for the treatment of active pouchitis. Dis Colon Rectum. 2007; 50(12): 2075-82.

65. Floch MH, Walker WA, Madsen K, Sanders ME, Macfarlane GT, Flint $\mathrm{HJ}$, et al. Recommendations for probiotic use-2011 update. J Clin Gastroenterol. 2011; 45 Suppl: S168-71. doi: 10 1097/MCG 0b013e318230928b.

66. Bartlett JG. Narrative review: The new epidemic of Clostridium difficileassociated enteric disease. Ann Intern Med. 2006; 145(10): 758-64.

67. Bartlett JG. Clinical practice: Antibiotic associated diarrhoea. N Engl J Med. 2002; 346(5): 334-9.

68. Gerding DN, Olson MM, Peterson LR, Teasley DG, Gebhard RL, Schwartz ML, et al. Clostridium difficile-associated diarrhea and colitis in adults. A prospective Case-controlled epidemiologic study. Arch Intern Med. 1986; 146(1): 95-100.

69. Szajewska H, Ruszczynski M, Radzikowski A. Probiotics in the prevention of antibiotic-associated diarrhea in children: a metaanalysis of randomized controlled trials. J Pediatr. 2006; 149(3): 36772.

70. Allen SJ, Martinez EG, Gregorio GV, Dans LF. Probiotics for treating acute infectious diarrhoea. Cochrane Database Syst. Rev. 2010; (11): CD003048 doi: 10 1002/14651858 CD003048 pub3.

71. Gao XW, Mubasher M, Fang CY, Reifer C, Miller LE. Dose-response efficacy of a proprietary probiotic formula of Lactobacillus acidophilus CL1285 and Lactobacillus casei LBC80R for antibiotic-associated diarrhea and Clostridium difficile-associated diarrhea prophylaxis in adult patients. Am J Gastroenterol. 2010; 105(7): 1636-41 doi: 10 1038/ajg 201011.

72. Psaradellis E, Sampalis J, Rampakakis E. Efficacy of BIO K+ CL1285 in the reduction of antibiotic associated diarrhea - a placebo controlled double-blind randomized, multi-center study. Arch Med Sci. 2010; 6(1): 56-64 doi: 10 5114/aoms 201013508.

73. Safdar N, Barigala R, Said A, McKinley L. Feasibility and tolerability of probiotics for prevention of antibiotic-associated diarrhoea in hospitalized US military veterans. J Clin Pharm Ther. 2008; 33(6): 663-8. doi: 10 1111/j 1365-2710 $200800980 \mathrm{x}$.

74. Beausoleil M, Fortier N, Guénette S, L'ecuyer A, Savoie M, Franco M, et al. Effect of a fermented milk combining Lactobacillus acidophilus Cl1285 and Lactobacillus casei in the prevention of antibioticassociated diarrhea: A randomized, double-blind, placebo-controlled trial. Can J Gastroenterol. 2007; 21(11): 732-6.

75. Hickson M, D'Souza AL, Muthu N, Rogers TR, Want S, Rajkumar C, et al. Use of probiotic Lactobacillus preparation to prevent diarrhoea associated with antibiotics: randomised double blind placebo controlled trial. BMJ. 2007; 335(7610): 80.
76. McFarland LV. Meta-analysis of probiotics for the prevention of antibiotic associated diarrhea and the treatment of Clostridium difficile disease. Am J Gastroenterol. 2006; 101(4): 812-22.

77. Goldenberg JZ, Ma SS, Saxton JD, Martzen MR, Vandvik PO, Thorlund $\mathrm{K}$, et al. Probiotics for the prevention of Clostridium difficile-associated diarrhea in adults and children. Cochrane Database Syst Rev. 2013; 5: CD006095 doi: 10 1002/14651858 CD006095 pub3.

78. Pattani R, Palda VA, Hwang SW, Shah PS. Probiotics for the prevention of antibiotic-associated diarrhea and Clostridium difficile infection among hospitalized patients: systematic review and meta-analysis. Open Med. 2013; 7(2): e56-67.

79. Suchy FJ, Brannon PM, Carpenter TO, Fernandez JR, Gilsanz V, Gould $\mathrm{JB}$, et al. National Institutes of Health Consensus Development Conference: Lactose Intolerance and Health. Ann Intern Med. 2010; 152(12): 792-6 doi: 10 7326/0003-4819-152-12-201006150-00248.

80. Ibarra A, Acha R, Calleja MT, Chiralt-Boix A, Wittig E. Optimization and shelf life of a low-lactose yogurt with Lactobacillus rhamnosus HN001. J Dairy Sci. 2012; 95(7): 3536-48. doi: 10 3168/jds 2011-5050.

81. Almeida CC, Lorena SL, Pavan CR Akasaka HM, Mesquita MA. Beneficial effects of long-term consumption of a probiotic combination of Lactobacillus casei Shirota and Bifidobacterium breve Yakult may persist after suspension of therapy in lactose-intolerant patients. Nutr Clin Pract. 2012; 27 (2): 247-51. doi: 10.1177/0884533612440289.

82. Ruchkina IN, Fadeeva NA, Parfenov AI, Shcherbakov PL, Gubina AV, Poleva NI, et al. [The role of small bowel microflora in the development of secondary lactase deficiency and the possibilities of its treatment with probiotics]. Ter Arkh. 2013; 85 (2): 21-26.

83. Pericleous M, Mandair D, Caplin ME. Diet and supplements and their impact on colorectal cancer. J Gastrointest Oncol. 2013; 4 (4):409-23. doi: 10.3978/j.issn.2078-6891.2013.003.

84. Rafter J, Bennett M, Caderni G, Clune Y, Hughes R, Karlsson PC, et al. Dietary synbiotics reduce cancer risk factors in polypectomized and colon cancer patients. Am J Clin Nutr. 2007; 85(2): 488-96.

85. Nagengast FM, Grubben MJ, van Munster IP. Role of bile acids in colorectal carcinogenesis. Eur J Cancer. 1995; 31A: 1067-70.

86. De Boever P, Wouters R, Verschaeve L, Berckmans P, Schoeters G, Verstraete W. Protective effect of the bile salt hydrolase-active Lactobacillus reuteri against bile salt cytotoxicity. Appl Microbiol Biotechnol. 2000; 53(6): 709-14.

87. Huycke MM, Gaskins HR. Commensal bacteria, redox stress, and colorectal cancer: mechanisms and models. Exp Biol Med (Maywood). 2004; 229(7): 586-97.

88. Vittorio GL. University of Milano Bicocca. ClinicalTrials.gov Identifier: NCT00936572. (Online) [Cited 2014 June 1]; Available from: https:// www.clinicaltrials.gov/

89. Valentini V. Catholic University of the Sacred Heart. ClinicalTrials. gov Identifier: NCT01579591. (Online) [Cited 2014 June 1]. Available from: https://www.clinicaltrials.gov/

90. Eren Z, Gurol Y, Sonmezoglu M, Eren HS, Celik G, Kantarci G. [Saccharomyces cerevisiae fungemia in an elderly patient following probiotic treatment]. Mikrobiyol Bul. 2014; 48(2): 351-5.

91. Santino I, Alari A, Bono S, Teti E, Marangi M, Bernardini A, et al. Saccharomyces cerevisiae fungemia, a possible consequence of the treatment of Clostridium difficile colitis with a probioticum. Int J Immunopathol Pharmacol. 2014; 27(1): 143-6. 
92. Thygesen JB, Glerup H, Tarp B. Saccharomyces boulardii fungemia caused by treatment with a probioticum. BMJ Case Rep. 2012. doi: 10.1136/bcr.06.2011.4412.

93. Österlund P, Ruotsalainen T, Korpela R, Saxelin M, Ollus A, Valta $\mathrm{P}$, et al. Lactobacillus supplementation for diarrhoea related to chemotherapy of colorectal cancer: a randomised study. Br J Cancer. 2007; 97 (8): 1028-1034.

94. Ishikawa H, Akedo I, Otani T, Suzuki T, Nakamura T, Takeyama I, et al. Randomized trial of dietary fiber and Lactobacillus casei administration for prevention of colorectal tumors. Int J Cancer. 2005; 116(5): 762-7.

95. Gianotti L, Morelli L, Galbiati F, Rocchetti S, Coppola S, Beneduce A, et al. A randomized double-blind trial on perioperative administration of probiotics in colorectal cancer patients. World J Gastroenterol. 2010; 16(2): 167-75.
96. Liu Z, Qin H, Yang Z, Xia Y, Liu W, Yang J, et al. Randomised clinical trial: the effects of perioperative probiotic treatment on barrier function and post-operative infectious complications in colorectal cancer surgery - a double-blind study. Aliment Pharmacol Ther. 2011; 33(1): 50-63.

97. Chitapanarux I, Chitapanarux $T$, Traisathit $P$, Kudumpee $S$, Tharavichitkul E, Lorvidhaya V. Randomized controlled trial of live lactobacillus acidophilus plus bifidobacterium bifidum in prophylaxis of diarrhea during radiotherapy in cervical cancer patients. Radiat Oncol. 2010; 5: 31.

98. Delia P, Sansotta G, Donato V, Frosina P, Messina G, De Renzis C, et al. Use of probiotics for prevention of radiation-induced diarrhea. W J Gastroenterol. 2007; 13(6): 912-5.

99. Salminen E, Elomaa I, Minkkinen J, Vapaatalo H, Salminen S. Prevention of intestinal integrity during radiotherapy using live Lactobacillus acidophilus cultures. Clin Radiol. 1988; 39(4): 435-7. 